tion, management of natural rain forest, tropical timber trade, government policies, an action plan on tropical forestry, and the system of protected areas in the region. The concluding chapter of this section sums up the critical points: it is possible to enlarge the size of the protected areas, lessen the pressure on natural forests by raising plantations of fastgrowing species, and manage natural forests on a sustained-yield basis. But these possibilities have always existed. Yet in recent years, the integrity of even the existing protected areas has not been maintained. Furthermore, there are few, if any, management plans for conservation of biological diversity in these areas.

Plantations of forest trees have consistently and significantly fallen below the established targets in many countries. Moreover, the plantations have failed to meet the needs of the rural poor, notably in India. Finally, although models of sustained-yield forestry exist, the assumptions of these models, as the editors themselves note, are often violated, leading to questionable management practices and forest degradation. Also, the claim that managed forests retain much of the original biodiversity is correct only under certain conditions. In summary, there are serious constraints on progress in conservation and use of forest resources, and a more extensive debate is needed on how such constraints might be overcome. Indeed, the stated aim of the book is to promote such a debate.

The second part provides information about problems and prospects of nature conservation in individual countries. Almost all major countries with significant amounts of tropical forests are covered. Their accounts provide an overview of the forests, biodiversity, existing and proposed protected areas, and conservation initiatives for individual countries. No other source offers such a comprehensive account for any of the countries of the region. Many chapters are written by, or based upon materials provided by the resident scientists of the countries concerned. Thus, the information is more credible than is usually the case in such general accounts.

Among the ten countries with the highest rates of tropical deforestation, five (Burma, India, Indonesia, Malaysia and Thailand) are in Asia. The book should provide a valuable and timely perspective to those engaged in finding a solution to the problems of deforestation and preservation of biodiversity. Conservation biologists should look forward to the publication of other volumes in this series

\title{
On shaky ground
}

\section{David Swinbanks}

Sixty Seconds That Will Change The World: The Coming Tokyo Earthquake. By Peter Hadfield. Sedgwick and Jackson: 1991. Pp.207. £17.60.

WHEN the next major earthquake hits Tokyo, what will be the consequences for Japan and the rest of the world? This is the daunting question Peter Hadfield attempts to answer. He not only predicts major destruction and deaths within Tokyo but also portrays a picture of dire economic consequences for the whole world.

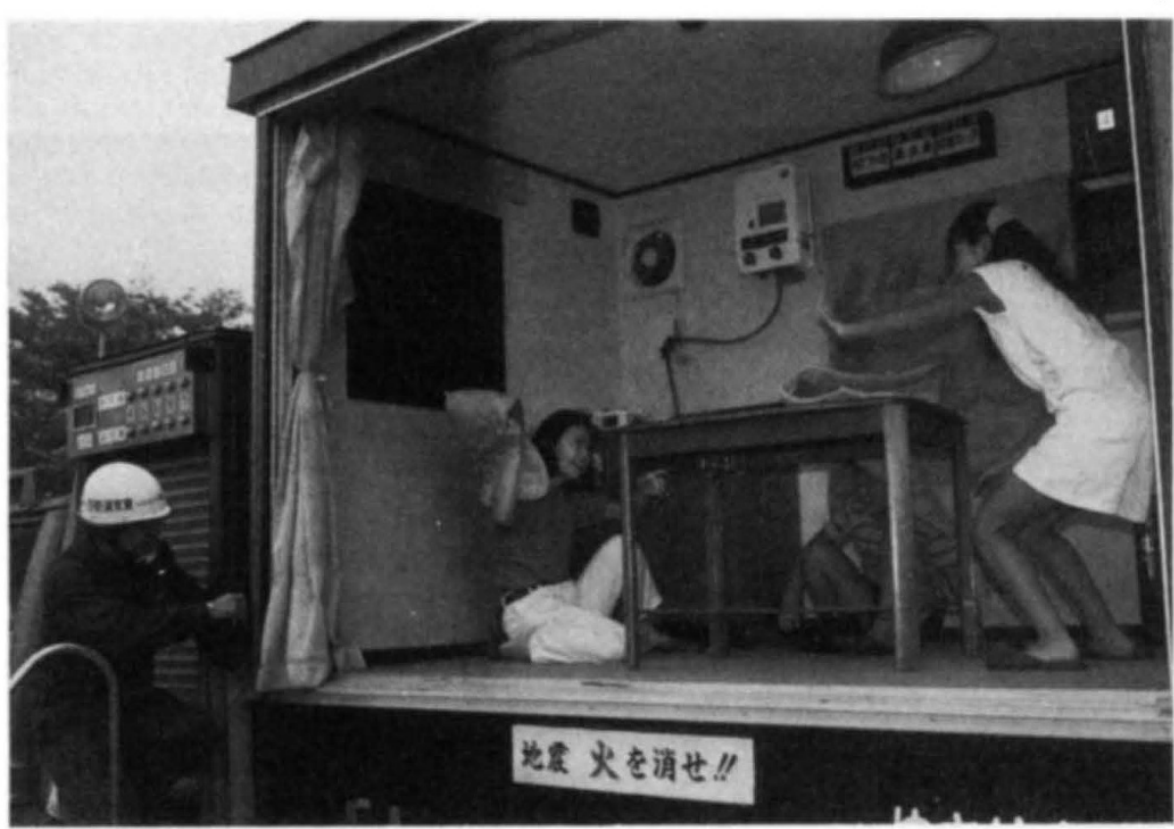

Earthquake drill - a shaking platform simulates the real thing for Tokyo inhabitants.

Much of what Hadfield says is based on the most recent evidence and reports available, as well as on extensive interviews with Japanese earthquake prediction and disaster prevention experts. Unfortunately the book, like its title, is dressed in sensationalism that may turn off the serious reader. This is a shame because he has a valid and very important message to put across.

Hadfield begins with a well documented description of the last major earthquake to hit Tokyo - the great Kanto earthquake of 1923,which killed about 140,000 people. He brings the full extent of that disaster to life with accounts of individual experiences based on newspaper reports from the time. And he brings home the terror of that day in 1923 when tens of thousands of people were roasted alive in Tokyo in fire storms that swept through the city after the earthquake.

He then argues that another major earthquake or string of earthquakes is bound to hit Tokyo in the next few decades. Few would disagree with this prediction, which is based on the opinions of Japan's leading scientific experts in the field. But Hadfield then gets onto shaky ground by predicting the consequences of such an earthquake.

For this he relies rather heavily on a 1988 report by Japan's National Land Agency. This is the only government report to look in detail at the consequences for Tokyo and surrounding areas of a repeat of the great Kanto earthquake. The report predicts 80,000 to 150,000 deaths, depending on the time of day the earthquake strikes, and the destruction of millions of buildings by fire. Some experts say the report underestimates the full extent of the disaster; others argue that most of Tokyo's modern buildings and roads, which have been built to withstand earthquakes, will fare better than predicted.

In the absence of a thorough independent assessment of the Land Agency report, its predictions are still open to question. But Hadfield then goes on to use a report produced by Tokai Bank, based on the Land Agency report, which says that a Tokyo earthquake will have disastrous economic repercussions for the world, and in particular the United States, because Japan will pull back hundreds of thousands of millions of dollars in overseas investments to reconstruct Tokyo.

Hadfield's gloomy picture may well be correct. But perhaps his greatest service has been to draw attention to a subject that requires much further study.

David Swinbanks is Publisher and Tokyo Correspondent of Nature in Japan. 